\title{
Current Trends of Development of the Regional Systems of Earth Remote Sensing
}

\author{
Yuri A. Maglinets*, \\ Gennady M. Tsibul'skii and Michael V. Noskov \\ Siberian Federal University \\ 79 Svobodny, Krasnoyarsk, 660041, Russia
}

Received 12.06.2016, received in revised form 06.08.2016, accepted 21.11.2016

The article discusses the construction of a regional multi-purpose remote monitoring of the Earth system as a problem-solving system. Formulate a set of factors that influence the establishment and operation of this class of systems, the basic function blocks.

Keywords: regional remote sensing systems, monitoring, geospatial object, spatial data infrastructure, regional authority.

\section{Современные тенденции}

\section{в построении региональных систем Д33}

\author{
Ю.А. Маглинец, Г.М. Цибульский, М.В. Носков \\ Сибирский федеральный университет \\ Россия, 660041, Красноярск, пр. Свободныий, 79
}

В статье обсуждаются вопросы построения региональной многоцелевой системь дистанционного мониторинга Земли как системы решения задач. Сформулирован набор факторов, влияющих на создание и функиионирование систем этого класса, рассмотрень основные функииональные блоки.

Ключевые слова: региональные системы Д3З, мониторинг, геопространственный объект, инфраструктура пространственных данных, региональное управление.

(C) Siberian Federal University. All rights reserved

* Corresponding author E-mail address: YMaglinets@sfu-kras.ru 


\section{Введение}

Актуальность создания региональных систем Д33 определяется наличием задач управления территориями на региональном, муниципальном уровнях и на уровне отдельных хозяйствующих субъектов. Следует отметить, что в последние годы в практике формирования и реализации ДЦП по использованию результатов космической деятельности в ряде субъектов Российской Федерации достигнут определенный прогресс. Если судить по открытым источникам, большинство проектов в области решения региональных задач дистанционного зондирования связаны с мониторингом земель сельскохозяйственного назначения. Среди других задач Д33 регионального характера выделяют мониторинг лесных пожаров, картирование паводковой обстановки, прогнозирование заторов льда на реках, обнаружение и мониторинг нефтяных загрязнений, прогноз урожайности сельскохозяйственных культур, георазведку, обнаружение и картирование вырубок леса, экологический контроль и др. [1-4]. Тем не менее единого, устоявшегося мнения о том, что должна представлять собой региональная система дистанционного зондирования (РСДЗ3), не сложилось.

Судя по публикациям, работы в рассматриваемой области в основном сводятся к построению информационно-поисковых систем, в то время как задачи регионального управления требуют организации не просто навигаторов в море информации, а полноценных систем, поддерживающих весь цикл принятия решений от постановки задачи управления геопространственным объектом (ГПО) до организации в полном объеме всего комплекса мероприятий по мониторингу и управлению. В статье предпринята попытка осмысления понятия РСДЗЗ и формирования требований к системам такого рода.

\section{Факторы, влияющие на построение РСД33}

Рассмотрим систему факторов, определяющих построение и функционирование РСДЗ3.

РСДЗ3 как управляющая система. Основной задачей РСДЗ3 выступает управление территориально распределенными объектами, включая мониторинг состояния, прогнозирование и планирование их развития. Следовательно, система должна обладать моделью поведения объекта, позволяющей в режиме реального времени (с дискретизацией, отвечающей темпам его изменения) определять, является ли текущее состояние объекта допустимым промежуточным состоянием на пути достижения целевого состояния, и в случае необходимости обеспечить принятие соответствующих корректирующих решений.

Разнородность и распределенность исходных данных. Говоря о космоснимках как основном виде исходных данных, следует отметить тенденции постоянного улучшения качественных и количественных характеристик международной космической группировки, включая и ее российский сегмент. Помимо космосъемки, для небольших территорий не утратили своей значимости авиационные методы дистанционного зондирования, растет интерес к использованию БПЛА. На пике внимания исследователей находятся всепогодные источники космоданных на основе радиолокационных датчиков.

Необходимым фактором для построения РСДЗЗ служит наличие базовой картографической основы и ее производных, где также благодаря усилиям Росреестра наметилась некоторая положительная динамика. 
Третьим источником информации является тематическая информация - как геопривязанная, так и без геопривязки, в том числе получаемая наземными методами, имеющаяся в базах данных профильных министерств и ведомств, научных организаций.

В общем случае при построении РСДЗЗ следует говорить о сверхбольших объемах слабо структурированных и зачастую не согласованных между собой данных.

Многочелевой характер системы определяется наличием разных уровней принятия решений и, как следствие, пользователей разного типа, преследующих различные системы целей. Таким образом, РСДЗ3 - решающая система, обеспечивающая для своих пользователей интерфейсы постановки задач.

Интеллектуальный характер системы. Сложность и разнообразие решаемых задач обуславливают способность системы к адаптации и самоорганизации. С учетом последнего должно осуществляться взаимодействие и с постановщиком задач, поскольку он является элементом контура управления (элементом решающей системы). В отношении его система должна быть активной. Это касается источников экспертного знания системы, поскольку в их функционирование не входит управление объектом, их (экспертов) нельзя вовлечь в решение задач системы в реальном масштабе времени.

Региональные факторы и особенности наблюдаемых объектов. Среди факторов, влияющих на выбор методов и средств решения задач Д33, следует отметить географическое расположение региона, его пространственную протяженность и особенности рельефа, а также размеры наблюдаемых объектов и степень их изменчивости во времени.

Взаимодействие региональных и федеральных систем. В первую очередь следует отметить общемировую тенденцию к построению РСДЗ3 как элементов ИПД соответствующего уровня. В РФ работы в этом направлении далеко не закончены, однако очевидно, что всякая вновь создаваемая РСДЗЗ должна обеспечить способы взаимодействия с существующей ИПД.

\section{РСДЗЗ как система постановки и решения задач}

Модель задачи (3) выглядит следующим образом [5]:

$$
3=<\mathrm{K}, \mathrm{K}_{\mathrm{a}}, \mathrm{K}_{\mathrm{r}}>\text {, }
$$

где $\mathrm{K}$ - необходимое для решения задачи знание об исследуемом объекте; $\mathrm{K}_{\mathrm{a}}$ - исходная информация об исследуемом объекте (актуальная модель исследуемого объекта); $K_{\mathrm{r}}$ - требуемая модель исследуемого объекта.

Сформулировать 3 - задать все элементы её модели. В этой связи РСДЗ3 должна обладать интерфейсом пользователя, осуществляющем поддержку пользователя при формулировке задачи и принятии решений. Система должна обеспечить поддержку различных уровней принятия управленческих решений и, как следствие, пользователей разного типа, преследующих различные цели, что определяет её многоцелевой характер. Таким образом, РСДЗЗ должна включать пользователя в контур управления геопространственным объектом, проявляя в отношении его требуемую активность.

Таким образом, постановка задачи должна начаться с формулировки Кт. При существующей неопределенности $\mathrm{K}_{\mathrm{r}}$ можно задать как совокупность ограничений и допущений: пространственные характеристики наблюдаемого объекта, развитие объекта во времени. Если мы 
ограничимся задачами сельхозпроизводителя, то К подготовительных и полевых работ можно представить, например, в виде следующих подцелей: $\mathrm{K}_{\mathrm{T1}}$ (планирование и подготовка), $\mathrm{K}_{\mathrm{T} 2}$ (весенние работы), $\mathrm{K}_{\mathrm{r} 3}$ (летние работы), $\mathrm{K}_{\mathrm{T} 4}$ (уборка урожая), $\mathrm{K}_{\mathrm{r} 5}$ (посадка озимых), $\mathrm{K}_{\text {т6 }}$ (планирование и подготовка земель к весенним работам). Дальнейшая детализация осуществляется на основе априорной информации о схеме, например, полей конкретного сельхозпроизводителя. Схема полей конкретного сельхозпроизводителя уточняется на этапе планирования на основе общей схемы полей сельхозрайона. Для каждого поля указывается некоторая стартовая точка либо некоторое множество точек (обучающая выборка), с которых и начинается восходящий анализ данных. В восходящем анализе уточняются границы полей, их содержание, определяются классы полей, строится, таким образом, тематическая карта полей сельхозпроизводителя с указанием изменений в сравнении с предыдущим наблюдением.

Восходящий и нисходящий анализ данных, рассмотренный выше, реализуется ансамблем агентов. Каждую цель дерева целей преследует соответствующий агент ансамбля. По сформулированной $\mathrm{K}_{\mathrm{r}}$ в многоагентной среде осуществляется конкурсный отбор корневого агента формулируемого дерева целей. Поскольку структура опознаваемого объекта известна агенту явно, то корневой агент осуществляет конкурсный отбор агентов, способных преследовать имеющиеся у него подцели для $\mathrm{K}_{\mathrm{r}}$. Таким образом, в поиске, управляемом целями, формируется дерево целей для текущей задачи. Адекватность коллектива агентов заданной проблеме области обеспечивается наличием механизмов порождения и уничтожения агентов и структурированием агентов по уровням обрабатываемых ими описаний наблюдаемых объектов.

После того как выбран первый терминальный агент, он активизируется: опознает релевантные его локальной цели исходные данные, означивает преследуемую цель и передает полученные результаты активизировавшему его надагенту. Надагент, получив данные от всех активированных им подагентов, проверяет их релевантность преследуемой им цели. Если надагенту удается означить преследуемую им цель, то полученный результат он передает уже своему надагенту. Тем самым реализуется поиск, управляемый данными, и формируется дерево решений исходной задачи. Если же исходные данные надагента не согласуются с его локальной целью, он определяет точку рассогласования и выбирает нового подагента, передавая ему управление. Таким образом, возникает взаимодействие восходящего и нисходящего поисков: образуется комбинированный поиск.

При достижении корневой вершины дерева решений при восходящем анализе, казалось бы, сняты все неопределенности формулировки исходной задачи, однако если наблюдаемый объект изменчив во времени, то соответствующие неопределенности остаются. Для устранения обсуждаемых неопределенностей через некоторый интервал времени $\Delta t$ перезапускается сформированный ансамбль агентов. Если наблюдаемый объект за $\Delta t$ претерпел существенные изменения, то следующий просмотр объекта осуществляется через $\Delta t,<\Delta t_{0}$, иначе $\Delta t>\Delta t_{0}$.

Сформированный в комбинированном поиске ансамбль агентов описывает структуру исследуемого объекта в некоторый момент времени $t_{0}$ начала наблюдения за ним. Кроме того, ансамбль описывает и структуру К для текущей задачи. Действительно, терминальные агенты описывают иконический уровень анализируемых изображений (пиксели и примитивы), а начиная с уровня сегментов описывается не только синтаксис анализируемых изображений, но 
и их семантика, соответствующая преследуемой цели $\mathrm{K}_{\mathrm{r}}$. И если бы объект был статичен во времени, то исходная задача была бы уже решена. Для статического объекта была бы статична и структура сформулированного ансамбля агентов. Однако, как правило, объект изменчив во времени. А следовательно, изменчива структура ансамбля агентов. Таким образом, возникает последовательность описаний предмета исходной задачи, которая описывает его временную изменчивость.

\section{Функциональные подсистемы РДЗ3}

Исходя из перечисленных выше факторов, сформулируем основные группы функций (функциональные подсистемы), которые должна обеспечивать РСДЗЗ:

- Подсистема поставки исходных данных из внешней среды.

- Подсистема преобразования исходной информации к виду, удобному для манипулирования.

- Подсистема взаимодействия с конечным пользователем.

- Подсистема, обеспечивающая внутреннее представление информации (база данных, база знаний).

- Подсистема управления ГПО.

- Подсистема управления программно-аппаратным комплексом.

Подсистема поставки исходных данных. В современных условиях акценты смещаются от использования собственных станций по приему «сырых» космоснимков к получению уже очищенной информации из различных источников, вплоть до получения готовых ответов на запросы пользователя из внешних источников. Таким образом, наряду с блоками управления сеансами связи со спутниками и т.п. в подсистеме должны присутствовать средства взаимодействия с внешними базами данных в самом широком смысле, построенные на основе использования стандартизованных протоколов и спецификаций, а также средства управления заказами на предоставление данных, по аналогии с отработанной в бизнесе информационной логистикой снабжения.

Подсистема преобразования исходной информации включает как средства предварительной обработки изображений и преобразования форматов, так и средства тематической интерпретации изображений, что вызывает необходимость, с одной стороны, вовлечения в процесс функционирования подсистемы экспертов по тематической интерпретации, с другой - использования техник экспертных систем: извлечения и формализации знаний.

Подсистема взаимодействия с конечным пользователем должна обладать свойством адаптивности, подстройки под требования пользователей с учетом рассмотренного выше многообразия видов пользователей и их запросов. Предполагает различные типы интерфейсов, включая возможности отображения векторных геоинформационных слоёв, растровых сцен, атрибутивной информации в тех сочетаниях, которые оптимальны в данный момент для данного пользователя.

Подсистема внутреннего представления информаџии базируется на комбинации технологий реляционных СУБД, геоинформационных систем, хранилищ данных, баз знаний. Хорошей основой для непротиворечивого представления информации является онтологический подход, позволяющий согласовывать семантику ГПО, комбинации растровых, вектор- 
ных и атрибутивных данных, формируя структуру корректного информационного запроса пользователя.

Подсистема управления ГПО включает средства представления ГПО как объекта мониторинга, настройки контрольных параметров, темпов актуализации, требований к исходным данным. Содержит собственно блок мониторинга, отвечающий за своевременное поступление информации, ее анализ, принятие управляющих решений и доведение их до соответствующих пользователей.

Подсистема управления программно-аппаратным комплексом позволяет решать задачи планирования, запуска на выполнение и контроля работы компонент программного обеспечения комплекса, автоматизированного сбора и анализа параметров состояния и характеристик работы инфраструктуры, выявления и локализации сбоев в работе информационной системы, накопления информации о параметрах состояния и характеристиках работы инфраструктуры и предоставления накопленной исторической информации для создания отчетов.

\section{Заключение}

Рассмотрены современные тенденции построения многоцелевых региональных систем дистанционного зондирования Земли. Сформулирована система факторов, влияющих на построение систем такого рода. Основной задачей РДЗ3 является управление территориально распределенными объектами. Это определяет требования к исходным данным и параметрам актуализации информации. Также важно отметить, что каждая РДЗ3 - это не автономная система, а система, находящаяся в условиях взаимодействия со множеством других систем различного масштаба, определяющих структуру формируемой в Российской Федерации ИПД.

Сформулированы требования к функциональному составу подсистем типовой РДЗ3. В настоящее время отдельные элементы функциональности из числа сформулированных выше реализованы в пилотном варианте в рамках выполнения проектов по организации подсистем РДЗ3 Красноярского края и Хакасии на базе центра приема и обработки спутниковой информации ИКИТ СФУ в рамках решения прикладных задач, связанных с сельскохозяйственным мониторингом и мониторингом динамики развития растительных сообществ [6-8].

\section{Список литературы}

[1] Лупян Е.А., Барталёв С.А. Спутниковые наблюдения Земли. Журнал. Земля и Вселенная, 2011, 5, 3-11 [Loupian E.A., Bartalëv S.A. Earth observation satellite, J. The Earth and The Universe, 2011, 5, 3-11 (in Russian)]

[2] Мурин С.А. К формированию системы мониторинга земель сельскохозяйственного назначения. Научный журнал. Аграрный вестник Урала, 2011, 10, 55-57 [Murin S.A. To the formation of monitoring system of agricultural lands, The scientific journal. Agrarian Bulletin of the Urals, 2011, 10, 55-57 (in Russian)]

[3] Шелестов А.Ю., Скакун С.В., Кравченко А.Н., Куссуль Н.Н. Распределенная система спутникового агромониторинга в Украине. Научный журнал. Современные проблемы дистанционного зондирования Земли из космоса, 2011, 8(1), 141-149 [Shelestov A.Yu., Skakun S.V., Kravchenko A.N., Kussul N.N. Distributed system for agriculture monitoring in Ukraine, The 
scientific journal. Modern problems of remote sensing of the Earth from space, 2011, 8(1), 141-149 (in Russian)]

[4] Маглинец Ю.А., Цибульский Г.М. Региональные системы дистанционного мониторинга. Особенности и решения.Двенадцатая Всероссийская открытая конференция «Современные проблемы дистанционного зондирования Земли из космоса», 2014, 8 [Magliner Y. A., Tsybul'skii G.M. Regional remote monitoring systems. All-Russian open conference «Modern problems of remote sensing of the Earth from space», 2014, 8 (in Russian)]

[5] Цибульский Г.М., Отв. ред. Москвичев В.В. Мультиагентный подход к анализу изображений. Новосибирск: Наука, 2005, 188 c. [Tsybul'skii G.M., Ex. Editor Moskvichev V.V. Multi-agent approach to image analysis. Novosibirsk, Nauka, 2005, 188 p. (in Russian)]

[6] Маглинец Ю.А., Мальцев Е.А., Брежнев Р.В., Соснин А.С., Цибульский Г.М., Шатрова К.В. Программно-технологическая инфраструктура представления и обработки геопространственной информации муниципального района. Современные проблемы дистанционного зондирования Земли из космоса, 2012, 9(3), 316-323 [Magliner Y. A., Mal'tsev, E.A., Brezhnev R.V., Sosnin A. S., Tsybul'skii G.M., Shatrova K. V. Software and technological infrastructure for the submission and processing of geospatial information of the municipal area. Modern problems of remote sensing of the Earth from space, 2012, 9(3), 316-323 (in Russian)]

[7] Maglinets Y.A., Mal'tsev E.A., Tsybul'skii G.M. Multipurpose geoinformation management system of Yenisei meridian territories. 2012. Pattern Recognition and Image Analysis, 22 (2), 318-322

[8] Федотова Е.В., Жолудев А.А., Изосимов В.Г., Шпирук Ю.Д., Маглинец Ю.А., Цибульский Г.М. Анализ сезонной динамики растительного покрова на основе данных дистанционного зондирования земли. Журнал Сибирского федерального университета. Техника и технологии, 2014, 7(8), 976-983 [Fedotova E.V., Zholudev A.A., Izosimov V.G., Shpiruk Y. D., Maglinets Y.A., Tsybul'skii G.M. The analysis of seasonal dynamics of vegetation cover based on remote sensing data of the earth. J. Sib. Fed. Univ. Eng. technol., 2014, 7(8), 976-983 (in Russian)] 